\title{
PENGARUH MEDIA PAPAN FLANEL MODIFIKASI TERHADAP KEMAMPUAN MENYUSUN KALIMAT PADA SISWA TUNARUNGU KELAS X DI SMALB BCD YPAC JEMBER
}

\author{
Alysa Amadea Isroso, Asrorul Mais \\ PLB FIP IKIP PGRI JEMBER \\ Email: Alysaamadea997@gmail.com
}

\begin{abstract}
Abstrak
Penelitian ini bertujuan untuk mengetahui pengaruh media papan flanel modifikasi terhadap kemampuan menyusun kalimat pada siswa tunarungu di SMALB BCD YPAC Jember. Penelitian ini merupakan penelitian kuantitatif dengan menggunakan metode eksperimen Single Subject Research (SSR). Penelitian ini dilaksanakan selama 3 minggu dengan tahapan minggu pertama baseline, minggu kedua serta ketiga intervensi. Subjek penelitian adalah siswa tunarungu ringan kelas $\mathrm{x}$ dengan inisial $\mathrm{ZD}$. Pada saat penelitian berlangsung metode pengumpulan data yang digunakan adalh observasi, tes praktik, serta dokumentasi. Hasil penelitian menunjukkan bahwa pada fase baseline ZD memperoleh skor presentase yaitu 35\%, $50 \%, 30 \%$, 30\%, dan 50\%. Setelah memasuki intervensi siswa mengalami peningkatan dengan perolehan skor tertinggi yaitu 95\% pada sesi ke 15. Dari hasil penelitian dapat dikatakan bahwa media papan flanel modifikasi berpengaruh terhadap kemampuan menyusun kalimat pada siswa tunarungu di SMALB BCD YPAC Jember.

Kata kunci: Tunarungu, media papan flanel modifikasi, menyusun kalimat
\end{abstract}

\section{PENDAHULUAN}

Manusia sebagai makhluk sosial tidaklah bisa lepas dari yang namanya komunikasi. Dengan adanya bahasa kita mampu melakukan kegiatan pada sesama manusia dengan baik. Dengan adanya bahasa manusia mampu mengekspresikan diri, menyampaikan ide dan pikiran, menyampaikan keinginan kepada orang lain dengan baik secara lisan ataupun tulisan.

Penggunaan bahasa yang baik dan benar dapat digunakan sebagai media bertukar informasi secara utuh kepada setiap manusia. Di sekolah luar biasa khususnya pada kelas yang menangani siswa tunarungu, kendala

bahasa adalah

permasalahan yang paling

utama pada saat proses belajar

mengajar. Keterbatasan

persepsi komunikasi dan

interaksi menjadi

pengaruh besar terhadap pema

haman siswa tentang pembelajar an yang disampaikan. Penggunaan kalimat ilmiah sering kali mendapat respon yang sulit dipahami oleh siswa sehingga guru harus menurunkan level kosa kata yang digunakan menggunakan kosa kata yang sangat sederhana sehingga siswa mampu menerima informasi tersebut dengan baik dan benar. Pada siswa tunarungu struktur kalimat yang digunakan 
dalam merangkai kalimat seringkali terbolak-balik sehingga tulisan yang mereka rangkai memiliki arti dan makna yang berbeda dengan semestinya. Sebelum mengajarkan siswa merangkai kosa kata dengan baik dan benar, siswa harus diajarkan mengenai penyusunan kalimat menggunakan SPOK (Subjek, Predikat, Objek, Keterangan) sebagai dasar acuan untuk membuat kalimat yang baik dan benar.

Menurut Hallahan dkk (dalam Hernawati , 2007, hlm. 2) siswa tunarungu adalah siswa yang mengalami hambatan mendengar, sehingga informasi yang didapat terhambat baik itu dengan alat bantu dengar ataupun tanpa alat bantu dengar. Ketunarunguan berkaitan dengan kondisi pendengaran individu, yaitu mengalami hambatan dalam memperoleh suara dari sekitar.

Berdasarkan observasi yang dilakukan di SMALB BCD YPAC Jember, siswa berinisial ZD belum mampu merangkai kalimat yang baik dan benar sesuai struktur SPOK (Subjek, Predikat, Objek, Keterangan). Hal ini menjadi bahan pemikiran dalam mencari solusi agar penulisan kalimat menjadi baik dan benar sesuai struktur SPOK serta mampu mencapai kompetensi yang diharapkan.

Kegiatan

belajar

mengajar yang dilakukan pada siswa tunarungu, berbeda dengan siswa pada sekolah umumnya. Siswa tunarungu lebih menyukai pada hal-hal yang bersifat visual. Media visual sangatlah beragam, menurut Mais (2016, hlm. 29) data visual tersebut dapat berupa data numerik, tabel, gambar umum, skema, atau bahkan sindiran dan kritik yang dapat divisualisasikan dalam bentuk media dua dimensi non-proyeksi.

Media yang digunakan untuk mengetahui kemampuan menyusun kalimat yang baik dan benar sesuai struktur SPOK adalah media papan flanel modifikasi. Media papan flanel adalah jenis visual. Bentuk dari media ini adalah dua dimensi serta dapat dipahami melalui indera penglihatan.

Menurut Sadiman, dkk (dalam Hanifah, 2015, hlm. 42) papan flanel adalah salah satu media papan boards yang menggunakan kain flanel sebagai papannya. Papan flanel merupakan media grafis yang efektif sekali untu $\mathrm{k}$ menyajikan pesan-pesan tertentu kepada sasaran tertentu pula. 
Sedangkan papan flanel modifikasi merupakan kain flanel yang dapat dipasang gambar, dilipat, dan dilepas dengan mudah sehingga dapat digunakan berkali-kali .Papan flanel modifikasi adalah media grafis yang efektif untuk menyajikan pembelajaran kepada siswa. Papan flanel ini dapat dilipat sehingga praktis.

Berdasarkan pemaparan diatas peneliti beranggapan bahwa papan flanel modifikasi dapat membantu pemahaman siswa pada penyusunan kalimat. Oleh sebab itu akan dilakukan penelitian mengenai "Pengaruh Media Papan Flanel Modifikasi Terhadap Kemampuan Menyusun Kalimat Pada Siswa Tunarungu Kelas $\mathrm{X}$ di SMALB BCD YPAC Jember.

\section{METODE}

Penelitian ini menggunakan desain A-B di mana A adalah kondisi baseline. Baseline merupakan perkiraan terbaik dari apa yang terjadi ketika perlakuan/intervensi belum dib erikn B adalah kondisi intervensi.

Kondisi intervensi adalah kon disi ketika suatu intervensi $t$ elah diberikan dan perilaku sasaran diukur dibawah kondisi tersebut .
Penelitian ini akan dilakukan di SMALB BCD YPAC Jember yang terletak di jalan imam bonjol no.42 kecamatan kaliwates kabupaten Jember. Waktu penelitian ini akan dilakukan 2 tahapan yaitu baseline dan tahapan intervensi. Pada tahapan baseline dilakukan sebanyak 5 sesi pengamatan selama satu minggu dengan waktu 45 menit disetiap sesi. Sedangkan pada tahapan intervensi dilakukan sebanyak 10 sesi dengan waktu 45 menit setiap sesi.

Penelitian ini dilakukan di SMALB BCD YPAC Jember. Subjek penelitian dalam hal ini adalah satu siswa kelas $\mathrm{X}$ dengaan inisial ZD. ZD adalah siswa tunarungu ringan di SMALB BCD YPAC Jember. ZD belum mengetahui konsep dasar menyusun kalimat yang baik dan benar sesuai dengan struktur SPOK. Penulisan kalimat ZD selalu terbolak balik atau tidak runtut sesuai dengan struktur SPOK. ZD dalam berkomunikasi menggunakan verbal, isyarat dan tidak menggunaka alat bantu dengar (ABD). Zd mampu berisyarat dengan baik.

Instrumen merupakan alat bantu yang digunakan oleh peneliti untuk mengumpulkan data dengan cara melakukan pengukuran, 
Purwanto (dalam Hanifah, 2015, hlm. 71). Alat bantu dalam penelitian ini merupakan tes tulis yang akan diberikan pada siswa sebagai subjek penelitian, yang berfungsi sebagai tolak ukur tingkat pemahaman siswa. Pengumpulan data ini dilakukan pada dua tahap yaitu baseline dan intervensi , dimana pada setiap tahap memiliki 5 sesi untuk baseline dan 10 sesi untuk intervensi.

Sunanto (2005, hlm. 93), merupakan tahap akhir dimana kesimpulan itu akan disimpulkan. Pada penelitian dengan subyek tunggal dengan data berbentuk grafik. Kemudian data dianalisis dengan perhitungan menggunakan analisis dalam kondisi dan analisis antar kondisi. Hal tersebut bertujun untuk memperoleh data secara jelas agar tidak mendapatkan nilai yang rancu dalam penelitian yang telah dilakukan dalam penyususnan ataupun pemahaman mkalimat SPOK (Subjek, Predikat, Objek, Keterngan) menggunakan papan flanel modifikasi

\section{HASIL DAN PEMBAHASAN}

Pada penelitian ini terdapat fase Baseline dan fase intervensi . Pada fase baseline pengambilan data dilakukan sebanyak 5 sesi dengan mendapatkan hasil presentase 35\%, 50\%, 30\%, 70\%, 50\%. Setelah data pada fase beseline diperoleh maka dilanjutkan pada fase intervensi. Pada fase intervensi dilakukan sebanyak 10 sesi dengan hasil data presentasi yaitu 70\%, 60\%, 75\%, 50\%, 75\%, 70\%, 70\%, 80\%, 80\%, 95\%. Untuk mengetahui kemampuan menyusun kalimat sesuai struktur SPOK dari data baseline (A) dan intervensi (B) maka disajikan dalam bentuk grafik sebagai berikut:

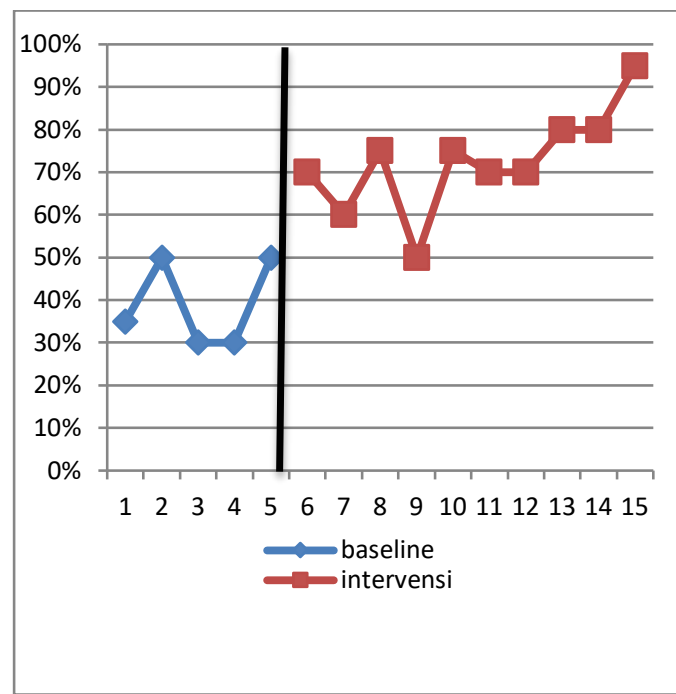


Rangkuman hasil analisis dalam

kondisi

\begin{tabular}{|c|c|}
\hline Kondisi & $\mathrm{A} / 1 \mathrm{~B} / 2$ \\
\hline Panjang kondisi & 5 \\
\hline $\begin{array}{l}\text { Estimasi kecenderungan } \\
\text { arah }\end{array}$ & \\
\hline \multirow[t]{2}{*}{ Kecenderungan stabilitas } & Variabel Variabel \\
\hline & $50 \%$ \\
\hline \multicolumn{2}{|l|}{ Jejak data } \\
\hline & $(+)$ \\
\hline \multirow{2}{*}{$\begin{array}{l}\text { Level stabilitas dan } \\
\text { rentang }\end{array}$} & Variabel Variabel \\
\hline & $50-95$ \\
\hline \multirow[t]{2}{*}{ Perubahan level } & $50-35$ \\
\hline & $(-15)$ \\
\hline
\end{tabular}

Rangkuman hasil analisis antar kondisi

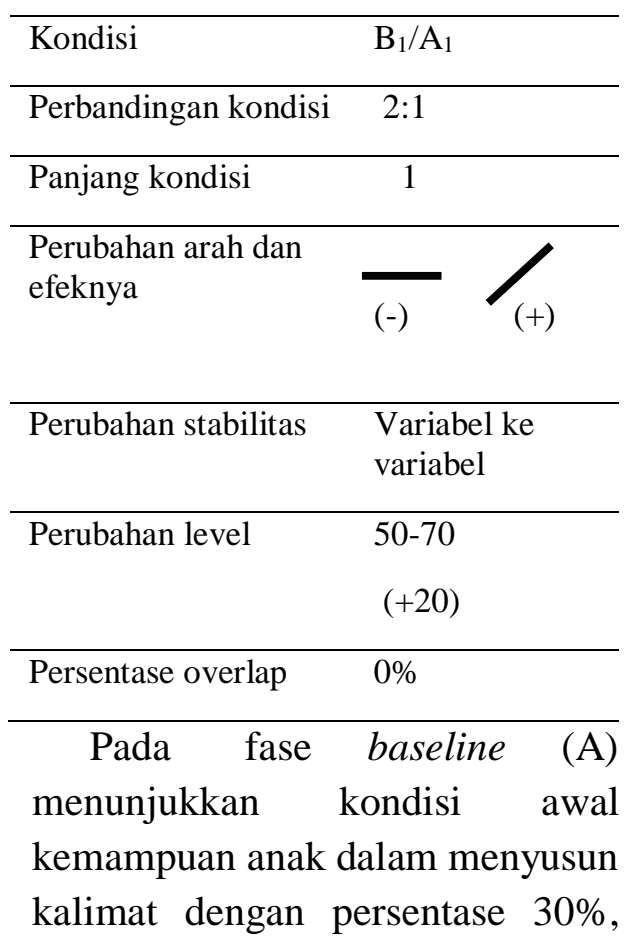

$50 \%, \quad 30 \%, \quad 30 \%$, dan 50\%. Persentase nilai terendah pada fase baseline (A) adalah 30\% dan persentase nilai tertinggi adalah 50\%. Sesi pertama hingga ketiga pada fase baseline siswa belum mampu memahami maksud dan tujuan dari media yang diberikan peneliti sehingga siswa hanya menebak dengan menempel gambar pada papan flanel modifikasi. Untuk sesi keempat dan lima belum ada perubahan pada siswa, dan siswa hanya menebak dengan menempelkan gambar pada papan flanel modifikasi.

Sedangkan ketika intervensi diberikan yaitu pada sesi keenam sampai dengan sesi kesepuluh siswa mengalami peningkatan dengan nilai presentase tertinggi yaitu $75 \%$. Pada sesi kesembilan siswa mengalami penurunan nilai presentase dengan perolehan nilai 50\%, dikarenakan kondisi kesehatan siswa yang menurun dan siswa tetap ingin melakukan praktik sehingga fokus siswa menurun dan mengakibatkan nilai presentase menurun. Pada sesi kesebelas sampai 14 siswa mendapatkan stabiliats nilai yaitu 70\%, 70\%, 80\% dan 80\% dengan adanya bantuan verbal isyarat siswa lebih mudah memahami apa yang disampaikan dan apa yang akan siswa kerjakan. 
Hasil penelitian

menunjukkan bahwa pengaruh media papan flanel modifikasi dalam pembelajaran menyusun kalimat berpengaruh terhadap siswa tunarungu ringan kelas $\mathrm{X}$ dengan inisial ZD di SMALB BCD YPAC Jember. Hal tersebut dapat dilihat pada peningkatan persentase kemampuan menyusun kalimat sebelum dan setelah mendapatkan intervensi berupa media papan flanel modifikasi. Mean level yang diperoleh siswa pada fase intervensi (B) yaitu 72,5 lebih tinggi jika dibandingkan dengan fase baseline 42,75.

Pada persentase overlap yang didapatkan adalah $0 \%$ yang menunjukkan bahwa intervensi yang diberikan pada siswa berpengaruh terhadap kemampuan menyusun kalimat sesuai struktur SPOK. Semakin kecil overlap yang didapat maka semakin baik pengaruh intervensi terhadap siswa. Dengan demikian perubahan level kemampuan siswa dalam menyusun kalimat mengalami peningkatan. Hal ini dipengaruhi oleh partisipasi siswa yang baik saat mengikuti pembelajaran dengan menggunakan media papan flanel modifikasi.

\section{PENUTUP}

\section{Simpulan}

Berdasarkan hasil perolehan data dalam bentuk analisis antar kondisi dan analisis visual dalam kondisi dapat disimpulkan bahwa media papan flanel modifikasi berpengaruh terhadap kemampuan menyusun kalimat pada siswa tunarungu di SMALB BCD YPAC Jember. Pada fase baseline (A) menunjukkan kondisi awal kemampuan anak dalam menyusun kalimat dengan persentase $30 \%$, 50\%, 30\%, 30\%, dan 50\%. Persentase nilai terendah pada fase baseline (A) adalah 30\% dan persentase nilai tertinggi adalah 50\%. Sesi pertama hingga ketiga pada fase baseline siswa belum mampu memahami maksud dan tujuan dari media yang diberikan peneliti sehingga siswa hanya menebak dengan menempel gambar pada papan flanel modifikasi. Untuk sesi keempat dan lima belum ada perubahan pada siswa, dan siswa hanya menebak dengan menempelkan gambar pada papan flanel modifikasi.

Setelah siswa diberikan perlakuan atau intervensi siswa mengalami peningkatan karena media papan flanel modifikasi yang mudah untuk dipahami siswa. Jadi dapat disimpulkan 
media papan flanel modifikasi berpengaruh terhadap kemampuan menyusun kalimat pada siswa tunarungu ringan dengan inisial ZD di SMALB BCD YPAC Jember.

\section{Saran}

Dari hasil simpulan diatas, dapat disarankan hal-hal sebagai berikut: (1) Sekolah diharapkan dapat menyediakan media pembelajaran yang aksesibel dan fleksibel sesuai kebutuhan siswa dalam meningkatkan kemampuan kognitif siswa. (2) Guru hendaknya lebih meningkatkan kreativitas dalam memodifikasi media pembelajaran agar siswa tertarik dan tidak bosan dalam mengikuti pembelajaran.

Bagi peneliti selanjutnya diharapkan mampu memodifikasi kembali media papan flanel modifikasi menjadi lebih aksesibel dan dapat digunakan untuk semua mata pelajaran.

\section{DAFTAR PUSTAKA}

Hanifah. (2015). Pengembangan Media Papan Flanel Pada Mata Pelajaran Membuat Lenan Rumah Tangga Bagi Siswa Tunagrahita SMPLB di SLB Negeri Pembina Yogayakarta. Skripsi diterbitkan. Yogyakarta: FIP Universitas Negeri Yogyakarta. (http://e.library.uny.ac.id/) diakses 01 juli 2020

Hernawati, Tati.

(2007).

Pengembangan, Kemampuan, Berbahasa, dan Berbicara, Anak, Tunarungu. Jurnal, Asesmen, dan, Intervensi Anak, Berkebutuhan, Khusus, 7 (1): 101-110.

Apriliani, Lia. (2013). Penggunaan, Media flash, card, dalam, Meningkatkan, Kemampuan, Berbahasa, pada Anak, Tunarungu, Kelas ,4,SDLB di, SLB, Negeri, Cicendo, Kota Bandung. , Skripsi, diterbitkan. Bandung: , FIP UPI. (http://repository.upi.edu/id/epr int/143) diakses 15 Juni 2020.

Ningsih, Triwahyu Endah. (2015). Upaya Meningkatkan Kemampuan Mengenal Kosa Kata Bahasa Inggris Melalui Penggunaan Media Papanz Flanel.

Skripsiditerbitkan.Bandung:FI

PUPI.(https://scholar.google.co .id/scholar?hl=id\&as_sdt=0\%2

C5\&q=upaya + meningkatkan $+\mathrm{k}$ emampuan+mengenai +kosa + ja ta+abahsa+inggris+melalui+pe nggunaan+media+papan+flanel \&btnG=\#d=gs_qabs\&u=\%23p \%3DOodVxMxwOioJ ) diakses 09 April 2020

Nurhadiyati, Arifah. (2014). Pengaruh Model Model Induktif Kata Bergambar Terhadap Keterampilan Menulis Kalimat Dasar Anak Tunarungu Kelas IV di SDLB B Karya Mulia II Surabaya. Skripsi diterbitkan. Surabaya:

FIP 
UNESA.(https://jurnalmahasis wa.unesa.ac.id/index.php/jurna

l-pendidikan-

khusus/article/view/8566)

diakses 06 Mei 2020.

Mais, Asrorul. (2016). Media

Pembelajaran Siswa

Berkebutuhan Khusus. Jember:

CV Pustaka Abadi.

Sunanto, Juang. (2005). Pengantar Penelitian dengan Subjek

Tunggal. Bandung: UPI. 